\title{
Space-station cuts leave research in lurch
}

\section{Tony Reichhardt, Washington}

Scientists who hope to work on the International Space Station fear that proposed budget cuts will severely impair the orbiting laboratory's research potential.

The researchers say that a new attempt to cut costs represents the biggest setback for the project since its last major redesign in 1993. The cost controls were introduced by the incoming Bush administration when it found that the station's price tag had soared to $\$ 4$ billion more than its planned level.

The White House has ordered NASA to find $\$ 4$ billion in savings over the next five years to offset the projected cost overruns. The savings are almost certain to reduce and delay research on the station.

According to one advisory group, if the impact on the station's capability is too drastic, "there will no longer be adequate justification for continued support of [the station] by the scientific community at large". The warning came from the scientific panel that oversees the Space Station Biological Research Project, a suite of lab facilities being developed at NASA's Ames Research Center near San Francisco, which is due to be installed on the station in stages over the next several years.

The working group's chairman, Martin Fettman of Colorado State University, wrote in a letter to NASA's chief of human spaceflight on 9 March that the group "is prepared to resign, effective immediately" if the research programme is cut back too far. "We believe the entire life-sciences community could turn its support away from [the station], and in fact become active campaigners against [it]" if the programme "continues to divert resources from science to solve construction problems".

The leverage exercised by such a warning may be limited by the fact that many scientists have opposed the station since its inception in 1984 (see Nature 307, 1-2;1984). But the latest rumblings come from individuals who have stuck with the project and supported some of NASA's claims for the viability of its research.

NASA plans to save half of the required $\$ 4$ billion by cancelling three key elements of the space station: a crew habitation module, a US-built rescue vehicle, and a propulsion module. Scrapping the first two means the station could house only three astronauts at a time instead of the planned six, unless some other rescue vehicle is attached to the station. Crew time is vital for conducting research, so this would dramatically affect the number of experiments that could be done, particularly in the biomedical sciences.

To make up the other $\$ 2$ billion, station managers are looking at several options, including cancelling or delaying some of

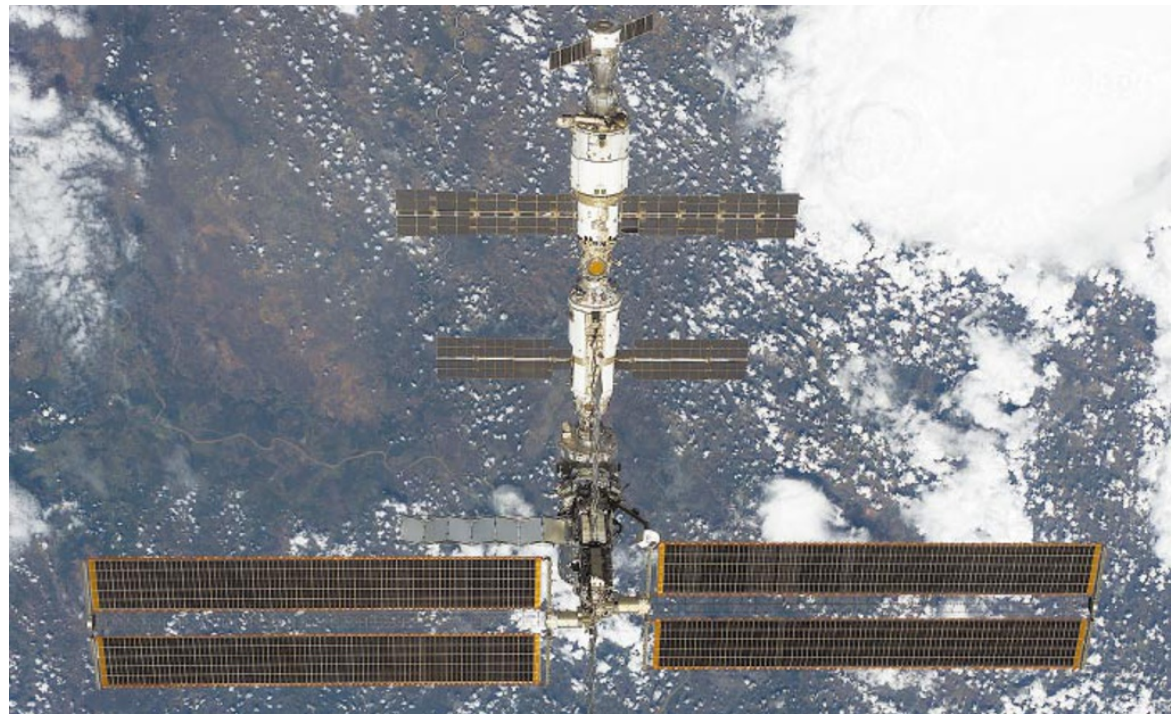

Over budget: the International Space Station must make savings of $\$ 4$ billion after cost overruns.

the large 'facility-class' research hardware planned for the station, or shifting the experiments to smaller, modular racks of the kind flown on past space-shuttle flights. But researchers say that either action would diminish the station's value as a laboratory.

Speaking to the National Academy of Sciences' Space Studies Board last week, Steve Isakowitz of the White House Office of Management and Budget said the cost overruns meant that the Bush administration effectively is committing only to a "core complete" version of the station, rather than the "assembly complete" version that was planned.

When assembly flight 10-A is completed in late 2003, NASA will have satisfied three key criteria, Isakowitz said. The station will be permanently occupied, the agency will have fulfilled its obligation to provide an attachment point for international modules, and the station will be better than any previous research facility in orbit. But any enhancements to the core design will have to come out of NASA's existing budget.

Some of the options under discussion have left life scientists in a near panic. One scenario entails scrapping a centrifuge considered essential for doing controlled studies of gravity's effect on animals and plants, along with much of the biological research equipment scheduled to be installed in the module that houses it. The module would instead be converted to living quarters for the crew, raising it back up to six.

Kathie Olsen, NASA's chief scientist, told the Space Studies Board that some of the options under discussion "would have a significant impact on the types of science that we'll be able to do", and may force the agency to eliminate entire fields of research from the station. But NASA officials advise patience, and hope that the station will eventually retain its capacity for a full crew and research programme.

\section{Israel plans new particle accelerator}

\section{Haim Watzman, Jerusalem}

A new particle accelerator will replace the 40-year-old research reactor at Israel's Soreq Nuclear Research Center by 2006, the government has announced.

The $\$ 24$ million facility will be used primarily as a source of neutrons, including cold neutrons, for materials scientists, structural biologists and other researchers, and for the production of isotopes.

Construction of the Soreq Applied Research Accelerator Facility (SARAF) is one of the first projects initiated by Telem, the Israeli National Forum of Research and Development Infrastructure.
Although still under design, SARAF is expected to consist primarily of a 50-70 mega-electron volt particle accelerator that will be able to generate proton beams with an intensity of 1-2 mA. The beam will be directed at a target to produce neutrons, whereas the old reactor produced them directly. The project's management will decide shortly whether the beam will come from a ring or a linear accelerator.

Zvi Kaplan, director of the Soreq centre, hopes to attract visiting research groups from the United States, Europe and Japan for pilot experiments to help Israeli researchers prepare the accelerator for use. 